\title{
FREUD, A SEXUALIDADE PERVERSO-POLIMORFA E A CRÍTICA AO DISCURSO DA DEGENERESCÊNCIA: REVISITANDO TENSÕES ENTRE PSICANÁLISE E PSIQUIATRIA
}

Cristiane Oliveira

Cristiane Oliveira Professora adjunta do Instituto de Psicologia da Ufba. Doutora em Saúde Coletiva (IMS/Uerj) com estágio doutoral na Université Paris Diderot/Paris 7. Pesquisadora do grupo Epos/ Genealogia, Subjetivações e Violências, e coordenadora da linha de pesquisa Corpo, Subjetividade e Biopolítica do grupo "Clínica Psicanalítica: controvérsias, interfaces e perspectivas", ambos cadastrados no $\mathrm{CNPq}$
RESUMO: Discute-se a crítica freudiana ao discurso da degenerescência através da análise da noção de sexualidade perverso-polimorfa no contexto das descontinuidades de sua teoria pulsional. Para cumprir esse propósito, revisita-se o discurso da degenerescência, discriminando a teia conceitual que lhe serve de suporte. Em seguida, esquadrinha-se, na obra freudiana, a contundente crítica a esse discurso, a partir da análise dos desdobramentos teórico-clínicos da emergência da noção de sexualidade perverso-polimorfa e seus rebatimentos na concepção de neurose e fantasia. Por fim, o trabalho aponta para a atualidade do gesto freudiano de explicitar tensões entre psicanálise e psiquiatria.

Palavras-chave: Psicanálise, psiquiatria, discurso da degenerescência, sexualidade, teoria pulsional freudiana.

ABSTRACT: Freud, the perverse-polymorphous sexuality and the critique of the degeneracy discourse: revisiting tensions between psychoanalysis and psychiatry. This paper discusses the Freudian critique to the discourse of degeneracy by analyzing the notion of perverse-polymorphous sexuality in the context of the discontinuities of his drive theory. To fulfill this purpose, the article revisits the discourse of degeneracy, detailing the conceptual net that supports it. Then, it scans in Freud, the severe critique to this discourse, from the analysis of the theoretical and clinical consequences of the emergence of the notion of perverse-polymorphous sexuality and its repercussions in the design of neurosis and fantasy. Finally, the study points to the relevance of the Freudian act of making tensions explicit between psychoanalysis and psychiatry.

Keywords: Psychoanalysis, psychiatry, degeneracy speech, sexuality, Freudian drive theory.

DOI - http://dx.doi.org/10.1590/S1516-14982016000100004 


\section{INTRODUÇÃO}

O presente texto analisa o posicionamento freudiano face ao discurso da degenerescência (MOREL, 1853, MAGNAN, 1876), marcado pela ideia de sexualidade perverso-polimorfa e circunstanciado pelas descontinuidades operadas na sua teoria pulsional. Com esse debate, Freud situava o privilégio dado à ontogênese em detrimento da filogênese na sua compreensão do funcionamento psíquico e do mal-estar na modernidade, tática que teve o mérito político de fazer resistência aos discursos e estratégias de poder que, servindo-se da degenerescência, constituíram o catastrófico cenário sociopolítico da primeira metade do século XX.

Essa estratégia de leitura teve como ponto de partida o comentário de Foucault (1976/2005, p.140-141) acerca da recusa freudiana do discurso da degenerescência e se serviu da análise que Joel Birman vem realizando acerca da posição da psicanálise no projeto (bio)político da modernidade (BIRMAN, 2000, 2003, 2007). Com esse percurso, pretende-se revisitar tensões entre psicanálise e psiquiatria, a fim de contribuir com o debate acerca das transformações na razão diagnóstica hegemônica na atualidade.

\section{O DISCURSO DA DEGENERESCÊNCIA}

Morel (1857), em seu Traité de dégénérescences physiques, intellectuelles et morales de l'espèce humaine, alimentava a pretensão de que a psiquiatria pudesse ser integrada à medicina geral, sendo oportuna a ideia que equiparava o homem à condição de todo e qualquer vivente, de modo a reformular o tratamento moral pineliano. A botânica, a neurologia, a anatomopatologia e a embriologia da época serviram de enquadre para que Morel pudesse levar a cabo seu interesse em analisar a condição humana, a partir do registro da espécie, distinguindo suas variações "naturais" e "patogênicas". A anatomopatologia comparada, em especial, deu a ele recursos para analisar a degradação tissular, metáfora da degeneração, a ser extrapolada para o campo moral. Partindo da observação de que os tecidos se degeneravam a partir de agentes intoxicantes nos animais, ele supõe que as “infrações à lei moral e a ausência de cultura intelectual” (MOREL, 1857, p.13) teriam os mesmos efeitos no homem.

Sustentado no criacionismo da metafísica cristã, Morel parte da ideia da existência de um tipo humano primitivo, representante da síntese perfeita da Criação que, submetido a certas condições degenerativas, geraria variações maléficas à espécie. Ele considerava que tais desvios eram produzidos pela violação à lei (divina), segundo a qual a multiplicação dos indivíduos deveria ter lugar exclusivamente no interior de uma mesma espécie, evitando com isso a produção de anormalidades. 
Seu pensamento se valia de noções como pureza e progresso da espécie humana para a defesa de que os cruzamentos miscigenantes levariam à degeneração, não havendo aí qualquer vestígio de uma interpretação darwinista da noção de "espécie humana”. Ele se vale da defesa bichatiana (BICHAT, 1805) da fragilidade da vida em face dos fatores de destruição, para afirmar que a especificidade de seu pensamento não residia na procura de causas degenerantes, mas na sua filiação com o sistema de pensamento que vê nessas causas a discordância, que ele entendia como fundamental, entre as instituições sociais e a natureza. Esse estado de degenerescência seria condicionado, no entanto, por uma causa ancestral que é a degradação na natureza humana, ameaça à finalidade última que seria manter-se fiel à perfeição de sua própria origem.

A hereditariedade é um tema já presente na medicina mental francesa no final do século XVIII, figurando no alienismo (pineliano e esquiroliano) como causa da loucura (SERPA-JUNIOR, 1998; BERCHERIE, 1989), mas ela ocupava lugar periférico no quadro dessas preocupações. Foi a partir das descobertas sobre as lesões cerebrais que ocasionavam a paralisia progressiva geral que, no campo psiquiátrico, acirrou-se a disputa entre o organicismo e seus oponentes, na tentativa de estabelecer o estatuto da loucura (CHIFFON, 2003). Morel recoloca a pergunta não mais nessas bases, mas no sentido de indagar por suas causas e mecanismos de desenvolvimento, abrindo nova possibilidade de pensar a loucura a partir de sua mecânica que, no entanto, não estava reduzida a um fisicalismo extremado. Pelo contrário, a teoria moreliana fazia uso do dialeto organicista como estratégia de suporte para uma visão da condição humana arraigada na metafísica.

A hereditariedade seria um dos traços fundamentais das degenerescências, que intensificaria a cada geração a extensão do mal, até que, por excesso, a natureza se encarregaria de conter o mal pela esterilização desses indivíduos. A hereditariedade também aparece, na classificação moreliana, como um subgrupo das causas de degeneração no qual certas disposições, não apenas a doença, seriam transmitidas e se manifestariam como degeneração. Mas a hereditariedade não era entendida como um desígnio exclusivo da natureza; antes, sua teoria se encontra ancorada na premissa de que o problema se encontrava justamente na “degradação moral”, que acabava por ocasionar a transmissão de certos traços patogênicos à descendência. A despeito dos fatores ambientais considerados, o cerne de sua tese é de que o homem é um ser degradado por sua própria responsabilidade; foi transgredindo a lei moral que a degenerescência se impôs. Aí ele diverge do raciocínio dos naturalistas, conservando, no entanto, os elementos desses que permitem ratificar a existência da degeneração.

A teoria da degenerescência de Morel estava subsidiada por uma visão fixista da espécie, razão pela qual ele afirmava que os degenerados acabariam por entrar 
em extinção. Além disso, Morel não concebia que a supremacia do homem face aos outros seres pudesse ser modificada. Essas marcas só podem ser entendidas quando inscritas no quadro do criacionismo que constituía seu pensamento. Reunidos, esses aspectos põem a teoria da degenerescência moreliana em rota de colisão com o darwinismo, marcado pela ideia de descontinuidade entre as espécies, dadas pela seleção natural. Além disso, coerente com sua leitura criacionista e favorecido pela atmosfera intelectual de sua época, Morel defendia a ideia de progresso, o que contrasta com a noção de acaso presente nas transformações das espécies na teoria darwinista (SERPA-JUNIOR, 1998). Como nos lembra Chiffon (2003), esta noção de degenerescência, se, por um lado, suscitava o risco de que a especificidade da medicina mental se perdesse em meio às preocupações da higiene, dada a polissemia que tal noção implicava, por outro, ela era altamente conveniente à pretensão de ancorar o fenômeno psicopatológico num substrato orgânico.

É apenas a partir da leitura que Magnan (1876) fará da teoria da degenerescência de Morel, quando o darwinismo já havia se difundido na França, que a noção de seleção natural, marcadamente descontínua, é assimilada pelo ideário do progresso. Isto porque a seleção natural será interpretada como o processo de eliminação dos inaptos em proveito da sobrevivência dos mais aptos que, de acordo com a nova leitura proposta por Magnan, estava condicionado ao progresso da espécie. Com Magnan, o axioma moreliano do tipo primitivo perfeito dá lugar a uma concepção evolucionista, segundo a qual a perfeição estaria no ponto de chegada, não no ponto de partida (SERPA-JUNIOR, 1998).

Magnan, no seu livro Recherches sur les centres nerveux, de 1876, vai remanejar a compreensão da degeneração, a partir da noção de desequilíbrio, possibilitando com isso alargar o espectro do que se poderia considerar degenerescência. É nesse sentido que o problema da genialidade é, por exemplo, recuperado como evidência de degeneração, pois mesmo indivíduos cuja capacidade intelectual e artística os colocaria acima de qualquer suspeita, sem quaisquer estigmas aparentes, padeceriam de certos desequilíbrios ao nível da vontade, um descontrole do instinto que poderia ocasionar atos extravagantes ou perigosos. Ainda de acordo com essa leitura magnaniana, nem mesmo o indivíduo medíocre escaparia ao rótulo de degenerado, pois na regularidade da sua conduta, alguns furos cognitivos, perceptivos e mesmo de memória indicariam uma falha de equilíbrio.

Defendendo-se da crítica de que ele teria alargado excessivamente os limites do grupo de “degenerados hereditários”, Magnan fará uso de um sistema explicativo bem diferente de seu antecessor: seu contra-argumento repousará no plano da ação, ou melhor, na irresistibilidade do impulso ao ato. Nessa perspectiva, ele vai manter no mesmo grupo manifestações patológicas que outrora estiveram em categorias nosológicas distintas. Ele contrasta o caso de um homem bem- 
-sucedido socialmente que aparentemente não portaria qualquer desequilíbrio mental, mas que na intimidade familiar se sentia irresistivelmente impelido a dizer palavras grosseiras, como que projetando impulsivamente para fora as imagens verbais — l'image tonale, a excitação sofrida no córtex cerebral — com outro que traduz o mesmo circuito nervoso em ato violento contra um transeunte qualquer. Segundo sua perspectiva, uma vez que uma falência da capacidade volitiva de barrar a força instintual se apresentava nos dois casos, não haveria qualquer diferença entre eles, razão pela qual a noção de degeneração por ele defendida — desequilíbrio/desarmonia — culminaria mesmo no alargamento da classe de degenerados.

De Morel a Magnan, vimos desaparecer o apelo metafísico à origem da degenerescência, para emergir uma descrição da figura da loucura hereditária degenerada, na qual se alargam os contornos do patológico. Desta forma, abandonou-se a ideia de "loucura parcial", localizada em algum lugar da personalidade, sem conexão com as demais instâncias e sua subsequente afirmação da totalidade da loucura para afirmar a anormalidade como novo objeto da psiquiatria. A interpretação para o que é perturbado na doença mental migra da faculdade da consciência para um “jogo entre o voluntário e o involuntário”, ou seja, para a faculdade da vontade.

Além disso, de forma coerente com esse "afrouxamento epistemológico" da psiquiatria, haverá uma expansão do seu domínio, pois não é mais a caça ao delírio, mas a caça de discrepâncias entre o comportamento do indivíduo e a "regularidade administrativa”, ou para com as "obrigações familiares” ou mesmo para com a "normatividade política e social". Efeito disso é a aproximação das doenças orgânicas que perturbam a volição, ou seja, a aproximação com o campo neurológico. Emerge então o domínio da neuropsiquiatria, que será institucionalizada um pouco mais tarde. A psiquiatria passará a ter como objeto a "doença da desordem”, ou seja, os ínfimos desvios individuais em relação a uma expectativa de homogeneidade social forjada no projeto (bio)político da modernidade (FOUCAULT, 1974-1975/2001).

\section{FREUD, A SEXUALIDADE PERVERSO-POLIMORFA \\ E A CRİTICA AO DISCURSO DA DEGENERESCÊNCIA}

Nos prefácios das sucessivas edições do texto Três ensaios sobre a teoria da sexualidade, publicado em 1905 e modificado ao longo dos 20 anos subsequentes, Freud (1905/1988) faz notar que o solo de constituição de sua investigação é a experiência psicanalítica. Esta coordenou as ênfases e supressões que ele imprimiu ao seu texto e do qual se ressentiram seus críticos à época, sobretudo pelo uso particular que fez da biologia para pensar os fenômenos sexuais. 
A defesa de uma preocupação centrada não na filogenética, mas na ontogênese, será crucial para entender sua posição crítica em relação ao peso atribuído à hereditariedade e ao seu correlato psicopatológico, a degeneração. No prefácio à terceira edição (1914/1988), ele demonstra uma interpretação acerca da noção de predisposição que, se de um lado, arrisca um reconhecimento de que a filogênese importa para os destinos do sujeito, por outro, ela estaria submetida, no seu pensamento, à condição de herdeira das vivências acumuladas ao longo da história filogenética. Para Freud (1905/1988), a experiência era o que, no fundo, poderia modificar a filogênese.

A crítica ao discurso da degenerescência há muito já havia sido esboçada. No artigo "Neuropsicoses de defesa" (1894/1988), Freud critica a perspectiva janetiana de que a divisão da consciência seria um traço primário da histeria causado pela degeneração, admitindo como explicação alternativa que a divisão decorreria de uma incompatibilidade da vida representativa do sujeito, ocasionada por um conflito de ordem sexual, que provocaria uma perturbação ao nível da vinculação entre afeto e representação. Os subsídios a essa crítica receberão maior detalhamento, dois anos depois, no artigo intitulado "A hereditariedade e a etiologia das neuroses" (FREUD, 1896a/1988), quando ele se utilizará de alguns argumentos, baseados na sua experiência como médico, a fim de atacar, pelo seu interior, a fragilidade da teoria da hereditariedade. O primeiro deles se dirigia à inespecificidade: haveria vários problemas aos quais se atribui origem nervosa, mas que na verdade não são dessa ordem. Ademais, atribuir a prova da hereditariedade de uma doença nervosa a toda e qualquer afecção nervosa encontrada na família seria anular o valor preditivo suposto à hereditariedade, já que seria impossível distinguir famílias livres de predisposição à doença nervosa daquelas cuja herança estaria comprometida. É daí que podemos extrair sua segunda contestação: a da generalização da degeneração (FREUD, 1896/1988).

Utilizando-se da distinção entre hereditariedade similar e hereditariedade dissimilar, Freud alega que há doenças em que a carga hereditária é inegável (no primeiro caso), mas há outras em que não se consegue estabelecer uma regularidade confiável entre as doenças apresentadas em determinada família e a doença específica de um indivíduo, inclusive não se podendo explicar com segurança por que uma pessoa pode sucumbir a uma doença sem ter uma carga hereditária, e outra, com a mesma carga hereditária, manter-se saudável. Freud complexifica o modelo etiológico da hereditariedade atribuindo-lhe três vetores: as precondições, condições indispensáveis na produção da neurose, mas são de caráter geral; as causas concorrentes, que estão na etiologia de vários distúrbios, mas não são específicas do distúrbio em causa; e as causas específicas, que são também indispensáveis, mas como o nome já diz, comparecem na etiologia de um distúrbio específico. Estava justificada a necessidade de investigação da 
“etiologia específica” da neurose e a necessidade de relativizar o peso atribuído à hereditariedade, recusando sua generalização como explicação etiológica para as neuroses e sublinhando a aquisição dessas no processo de constituição subjetiva. Desde lá ele já sabia que a hereditariedade representava um niilismo terapêutico ao qual não queria se filiar, ao contrário da aposta na "via de acesso", que poderia ser aberta pela busca da etiologia específica. Sua aposta residia não na história da espécie, mas na história da constituição da subjetividade.

Nos Três ensaios..., reaparece a crítica à teoria da degeneração. Em sua leitura sobre a "inversão sexual”, Freud (1905/1988) vai criticar a interpretação psiquiátrica que a considerava uma manifestação da degeneração. Considerando-a como uma atribuição pertinente apenas quando houvesse múltiplas incidências mórbidas no mesmo indivíduo e quando sua capacidade funcional estivesse comprometida, Freud critica a generalização e a importância dada à degeneração como fator explicativo para a patologia mental.

Freud critica Magnan como tendo estendido a degeneração ao que poderia ser considerado mesmo como funcionamento nervoso nobre e exemplar. O enquadramento do "invertido" como degenerado não procederia nem mesmo se pensado no interior da própria teoria da degenerescência, pois não atendia nem mesmo aos critérios já discriminados — concomitância de desvios em relação à norma e comprometimento da capacidade de funcionamento e de sobrevivência. Freud recorre ainda ao argumento antropológico segundo o qual a "inversão sexual" era muito frequente e culturalmente valorizada nos povos antigos, razão pela qual não poderia ser atribuída à degeneração. Mas o argumento decisivo que lhe servirá de contraponto ao discurso da degenerescência reside na ideia da disposição sexual perverso-polimorfa.

Distanciando-se do discurso da degenerescência, Freud vai afirmar, no seu trabalho de 1905, os Três ensaios..., a partir de sua leitura dos "desvios sexuais", que a pulsão não possui objeto fixo. No momento inicial da vida humana, inclusive, a pulsão seria independente do seu objeto, detectável por Freud a partir das experiências de satisfação sexual, codificadas por ele a partir do conceito de autoerotismo.

Tal afirmação pretendia esmaecer a ligação entre esses termos, de modo a fragilizar o argumento da psicopatologia da época, cuja nosografia estabelecia objeto e finalidade fixos para a pulsão sexual, fora dos quais todo comportamento deveria ser considerado uma “aberração”. As ditas transgressões sexuais seriam muito mais frequentes na vida cotidiana, não merecendo por isso o designativo de patológico. Assim, a fixação de libido, a inversão, a transgressão anatômica fariam parte do repertório psíquico corriqueiro da pulsão sexual. Freud tenta desvencilhar a noção de desvio da noção de patologia, criticando a superpatologização que o discurso da degenerescência teria imprimido ao âmbito sexual. 
Nem mesmo nos casos em que a pulsão sexual desafia as resistências psíquicas - "vergonha, asco, horror ou dor" (FREUD, 1905/1988, p.152) - para se satisfazer, e que poderiam merecer o designativo de patologia (ele cita os atos, não as categorias nosográficas: "lamber excrementos, abusar de cadáveres"), ele admite como necessária a conexão com a doença mental (ou seja, com a degeneração). Para Freud, a perversão se denominaria patológica na presença de atributos (exclusividade e fixação) que regeriam a vida sexual dos indivíduos, ou seja, a perversão poderia se configurar como patológica apenas quando o alvo desviante fixasse o sujeito numa relação de exclusividade. Com efeito, sem recusar o termo "perversão", pois sustenta a ideia de transgressão sexual do alvo e dos objetos, ele lhe atribui novo significado :ela sai do registro psicopatológico e se inscreve na dinâmica psíquica montada para satisfazer o imperativo pulsional de satisfação. Dessa forma, as perversões seriam emblemáticas da "onipotência do amor" (FREUD, 1905/1988, p.153).

Em 1915, no texto A pulsão e suas vicissitudes, Freud (1915/1988) vai afirmar que a pulsão é uma força sedenta de satisfação, que não é necessariamente direta. A pulsão sexual estaria atrelada ao trabalho de inscrição de traços psíquicos, pois provocava uma "exigência de trabalho" ao psiquismo. Contrastando com o discurso vigente à época sobre a psicopatologia sexual, Freud vai afirmar que a sexualidade infantil, na sua polimorfia-perversa, refletiria a disposição subjetiva por excelência em relação ao desejo sexual.

A defesa freudiana de que a neurose seria o negativo da perversão, quer dizer, que o sintoma substituiria uma disposição à satisfação irrefreável da pulsão sexual, está subsidiada pela análise da persistência no adulto dessa disposição perversa infantil. O indivíduo seria, portanto, de saída, marcado pela experiência autoerótica, podendo ser sucedida por uma parcialização das pulsões, cujos objetos — não-fixos, nem suficientes — se dirigiriam à finalidade de satisfação, sempre incompleta. A integração das pulsões pela genitalidade se constituiria como um ponto de chegada dessa normatividade sexual engendrada na infância. A experiência sexual infantil, cujo estatuto aparece agora reafirmado, é o espaço de maior visibilidade dessa polimorfia, persistindo algo de perverso na vida sexual do adulto normal, de modo que as estratégias de normalização psíquicas e sociais para o agenciamento do excesso sexual estariam sempre fadadas a algum nível de fracasso.

Freud, no entanto, hesitou em afirmar a existência da sexualidade infantil. Em Observações adicionais sobre as neuropsicoses de defesa, de 1896, ainda sob a influência da teoria da sedução, ele vai discutir a natureza dos traumas sexuais - cuja existência já havia sido afirmada no texto de 1894 sobre o tema das neuropsicoses de defesa - , mas sobretudo vai defender sua origem na tenra infância (FREUD, 1896b/1988). As reminiscências que apareciam nos relatos de seus 
pacientes lhe ofereceram um caminho que o conduziu a pensar que experiências sexuais ativas originavam a neurose obsessiva, o que contrastava com a histeria, cuja causa específica deveria ser situada numa vivência sexual passiva, circunscrevendo aí a experiência sexual infantil como uma aparição precipitada pela presença de um adulto. ${ }^{1}$

Uma mudança na direção da assunção da tese da sexualidade infantil aparece na Carta 75, de 1897, quando Freud (1897/1988) a insere como parte do desenvolvimento da criança, a partir da noção de "zona sexual”, identificada, então, à genitalidade. Freud já pensava à época, por exemplo, que a passagem da infância para a adolescência para as meninas culminaria com a extinção de uma zona sexual, o clitóris (que se encontrava identificado ao masculino), sensível na infância, afirmação que aponta para certos impasses da teoria freudiana em relação à feminilidade, cuja necessária revisão crítica ${ }^{2}$ escapa, no entanto, ao escopo deste trabalho. A ideia de uma normatividade sexual na infância está, portanto, esboçada.

Um ano depois, no seu artigo $A$ sexualidade na etiologia das neuroses, de 1898, a existência de vida sexual na infância aparece com certa autonomia, ainda que de modo cauteloso, quando Freud (1898/1988) enfatiza que todas as manifestações sexuais psíquicas e algumas somáticas podem ser encontradas nessa fase da vida. A ideia comum de que a sexualidade infantil era uma manifestação fora do lugar foi por ele interpretada nesse artigo menos como algo da ordem da vida sexual da criança em si do que à regulação social dessa função. A exigência civilizatória de utilização da pulsão sexual a serviço de "grandes fins culturais" está situada, desde esse momento, como aquilo que torna compreensível a conversão da experiência sexual infantil em motivo de adoecimento psíquico.

Essa preocupação de Freud com mal-estar na modernidade ${ }^{3}$ reaparecerá dez anos mais tarde, no texto Moral sexual civilizada e doença nervosa moderna, de 1908.

\footnotetext{
${ }^{1}$ Em nota de rodapé, acrescentada em 1924, Freud reafirma a retificação que fez na sua compreensão da neurose, a partir da desmontagem da teoria da sedução que regia essa consideração acerca da sexualidade infantil, colocando em relevo o papel da fantasia na dinâmica psíquica, o que possibilitou a autonomização da vida sexual infantil em relação aos adultos, retirando-a definitivamente de sua aura psicopatológica para pensá-la em sua normatividade. Ainda assim, é interessante notar, no artigo de 1896, que Freud já havia desenvolvido uma compreensão bastante refinada acerca do funcionamento psíquico, presente, por exemplo, na ideia de que o efeito traumático viria a posteriori como uma reativação dos traços mnêmicos impressos no psiquismo desde a mais tenra infância, marcando desde aí a diferença do pensamento freudiano em relação à teoria da degeneração, apontando para uma concepção do aparelho psíquico que o aproximava de um aparelho de escrita (DERRIDA, 2001), cuja mobilidade era propiciada pela economia pulsional.

${ }^{2}$ Ver Nunes (2000); Birman (2001).

3 Adotaremos a tradução que Birman (2003) faz do termo "civilização" por "modernidade", por entendê-lo mais sensível à capacidade de leitura crítica de Freud aos impasses subjetivos e sociais do projeto moderno que tanto o inquietaram desde os escritos da psicanálise.
} 
Analisando as considerações dos médicos acerca da relação entre civilização e doença nervosa, ele questiona o julgamento comum que atribuía ao estilo de vida acelerado, competitivo, repleto de conflitos religiosos e sociais, ao excesso de trabalho - enfim, a razão de ser do nervosismo crescente. Reafirma aí que, ainda que esses fatores não estejam incorretos, seriam imprecisos, pois seria a repressão sexual dos civilizados, imposta pela moral sexual "civilizada", a causa específica e perturbadora da doença nervosa (FREUD, 1908/1988). Nesse particular, fará uma crítica audaciosa ao casamento monogâmico imposto pela moralidade sexual vigente na modernidade, descortinando uma leitura fina dos impasses que foram colocados pela exigência (biopolítica) à família e, em especial, à mulher, que, pouco a pouco, fora se constituindo, a partir do século XVIII. Assumindo que finalidade da pulsão sexual era, primariamente, o prazer, e apenas a posteriori a reprodução poderia vir a se organizar, Freud afirmava, ainda no texto de 1908, que era impossível homogeneizar a conduta sexual dos indivíduos, de modo que parte do sofrimento ao qual estavam submetidos se originaria não na condição da hereditariedade, mas na inclinação de corresponder a um ideal normativo.

As restrições impostas à vida pré-conjugal — a abstinência, a contenção das demonstrações eróticas, etc. — não só não seriam resolvidas com a promessa higiênica e moral do casamento, idealmente voltada para sanar os problemas que a moral sexual civilizada instituía, mas intensificavam seus efeitos. As restrições sexuais persistiriam no casamento, precipitadas pela necessidade de controle da procriação, mas depois pela fragilização paulatina do desejo e até mesmo da afinidade psíquica entre os cônjuges. Tais restrições geravam uma necessidade de encontrar outros destinos para a força imperiosa das pulsões sexuais, que, por definição eram uma força constante, como o recurso à satisfação dessa demanda.

As atividades sexuais extraconjugais (prostituição, masturbação, infidelidade), postas em prática, de modo predominante, pela dupla moral masculina, mas também o recurso à doença nervosa, mais prevalente entre as mulheres, e a sublimação, que expressava os altos fins da cultura, se colocavam como os principais destinos da satisfação sexual frustrada pelo casamento. O casamento estaria atravessado pela paradoxal condição de ser o repositório cultural das pulsões sexuais e, ao mesmo tempo, a fonte de uma grande miséria subjetiva, marcada pela frustração do ideal que em princípio a definiria. Por fim, esse mal-estar no interior da vida conjugal afetaria diretamente os filhos, pois estariam expostos a uma pesada ambivalência afetiva, o que acarretaria uma espécie de pane na economia erótica familiar como um dos efeitos paradoxais da moral sexual civilizada.

Mas essa lucidez freudiana em relação à moral sexual moderna traz outra consideração a ser feita na torção do seu pensamento contra ele mesmo. Pode- 
mos ler em Freud um esforço de se desvencilhar dos embaraços que a ideia de "normalidade" sexual lhe impunha. Apesar de sua posição crítica em relação à moral sexual moderna, ele foi atravessado por suas prescrições normalizantes.

Freud fala em "perigos do pré-prazer"; advoga a ideia de que a perversidade polimorfa pela via educativa poderia manter a pulsão em rumos coerentes com os ideais civilizatórios; demonstra ambiguidade em relação ao poder normativo da heterossexualidade; prescreve destinos subjetivos possíveis para a feminilidade, tomando a maternidade como seu desfecho mais adequado. Ademais, a despeito de sua posição crítica em relação à degenerescência, o discurso freudiano fez reverberar a fustigação moderna em torno da questão sexual, enunciada por Foucault (1976/2005) como "vontade de saber", razão pela qual fora acusado por seus detratores de pansexualista. Foi o risco que correu quando tentou pensar o aparelho psíquico de maneira indissociável do mal-estar produzido na modernidade.

Mesmo levando em consideração as distinções traçadas por Freud no seu texto Três ensaios sobre a sexualidade, de 1905, entre instinto e pulsão — quais sejam, a inespecificidade dos objetos e a condição de parcialidade das pulsões - que tornariam a perversão a regra e não a exceção, Birman (2007) salienta que ambos estavam referidos à matriz da força vital. O sexual esteve durante todo o desenvolvimento da primeira metapsicologia significado como a "materialização maior da vitalidade, em oposição tanto ao registro do espírito quanto ao da natureza inorgânica” (BIRMAN, 2007, p.542).

Na proposição de um primeiro dualismo pulsional, momento em que começa a trabalhar com a formação do ego, Freud (1910/1988) nos apresenta a tensão entre a exigência de satisfação do inconsciente e as funções conciliatórias da consciência, através da oposição entre as pulsões sexuais e as pulsões de autoconversação. Analisando um caso de cegueira psicogênica, Freud apresentará como mecanismo explicativo para a produção do sintoma a ideia de conflito pulsional, solução de compromisso que demonstrava que a força da pulsão sexual era tão imperiosa em face do ego que era capaz de promover, no caso em questão, uma “autossugestão inconsciente de que estavam cegas". A oposição psicodinâmica, que então se instituía entre pulsões sexuais e pulsões do ego, já havia se insinuado desde seus primeiros escritos psicanalíticos (alguns dos quais foram mencionados aqui), revelando, como Birman (2007) faz notar, que a pulsão sexual dominava a economia psíquica, o que foi utilizado pelos seus críticos para enquadrá-lo como pansexualista, afirmação que ele não cessou de contestar até bem perto do fim de sua vida.

Em 1918, numa entrevista a uma jornalista húngara, Freud (1918/1995a) afirmou a sexualidade como tendo papel fundamental na constituição da neurose, o que seria bem diferente da afirmação de que tudo é sexual no homem 
para a psicanálise. Em 1920, escreve uma nota a Claparède - que escreveu uma introdução ao pensamento freudiano na primeira tradução francesa do texto Cinco lições de psicanálise, publicada na Revue de Genève, acusando-o de deformar suas ideias acerca do lugar do sexual no funcionamento mental. Freud afirmava que a posição do comentarista, segundo a qual o pensamento psicanalítico compreendia ser a libido — tomada como sinônimo de pulsão sexual — a força fundamental de todas as manifestações psíquicas, era equivocada na medida em que seu conceito de libido não era extensível, como o era para Jung, a todo o funcionamento psíquico.

A partir do texto Introdução ao narcisismo (1914/1988), Freud nos apresenta este primeiro modelo como insuficiente, uma vez que a libido também se concentrava no eu, fruto das análises que vinha desenvolvendo sobre a paranoia e sobre a distinção entre o luto e a melancolia. Ele recoloca, então, duas modalidades de pulsão sexual: libido do eu e libido objetal, mantendo-as, no entanto, atreladas ao primeiro dualismo já comentado. Mas a ruptura com a matriz da força vital viria só após a década de 1920, com a formulação do conceito de pulsão de morte, no seu Além do princípio do prazer (FREUD, 1920/1988), no qual é possível identificar uma ruptura radical com o vitalismo que habitava seu tempo. Um tanto distinto do modelo conflitual do primeiro dualismo pulsional, o erótico aparece submetido ao trabalho da pulsão de morte, força psíquica que tende à descarga ao grau zero, regulada que seria pelo princípio da inércia, colocando como exigência o trabalho permanente da pulsão de vida, que convoca o psiquismo ao trabalho de ligação, sem o qual a vida se tornaria inviável.

No quarto prefácio dos Três ensaios..., em 1920, ele sublinha outra vez os mal-entendidos que a aproximação com a biologia gerou e, mais ainda, a dificuldade de compreender seus achados como indissociáveis da análise. Como principal deles, estaria o rótulo de pansexualista, fruto, segundo sua interpretação nesse momento, da incompreensão em que esteve mergulhada a "ampliação" do conceito de sexualidade elaborada por ele - realizada a partir da análise das crianças e dos perversos — , segundo a qual a sexualidade vai assumir o sentido do Eros platônico.

É apenas quando o conceito de pulsão de morte se coloca, convocado pelos impasses da experiência como psicanalista, que ele pôde fazer uma retificação quanto ao peso que atribui à sexualidade na vida psíquica, deixando entrever que ali reconhecia um passado pansexualista. A noção de conflito que é subjacente ao novo dualismo que se apresenta entre pulsão de vida e de morte é, de forma mais incisiva do que na primeira tópica, uma noção que aponta para um mero antagonismo, mas para uma aporia na solidariedade tensionada entre essas forças que constituem o psiquismo. Em entrevista concedida ao jornalista americano George Sylvester Viereck, em 1926, ela reafirma tal posição: 
“A Morte é companheira do Amor. Juntos eles regem o mundo. Isto é o que diz o meu livro Além do princípio do prazer. No começo, a psicanálise supôs que o Amor tinha toda a importância. Agora sabemos que a Morte é igualmente importante (FREUD, 1926/1995b, p. 57).

\section{PSIQUIATRIA E PSICANÁLISE: VELHAS TENSÕES, NOVOS EMBATES}

O percurso realizado neste artigo procurou revisitar tensões entre o discurso médico-psiquiátrico e o psicanalítico, tomando o debate entre a teoria da degenerescência e a teoria freudiana da sexualidade perverso-polimorfa, a fim de resgatar uma memória de divergências ético-políticas entre esses dois campos, que foram uma das condições de possibilidade para a constituição da psicanálise como teoria e como práxis. As controvérsias que constituíram a reviravolta no campo psiquiátrico na segunda metade do século XX, sobretudo a partir da década de 1980, carregam implícita ou explicitamente essa memória discursiva, calcada que está numa ontologia organicista, recodificada pelo discurso das neurociências e subsidiada pela medicina baseada em evidências.

De modo mais contundente, a rebiologização da psiquiatria se faz bem evidente, no início da década de 1980, com o lançamento da terceira versão do DSM (SPITZER, 1980), que representou um acontecimento, no sentido foucaultiano do termo (FOUCAULT, 1967/2005). Muito barulho se produziu em torno daquele documento, que reconfigura a razão diagnóstica, suprimindo quaisquer matizes de extração psicadinâmica, toma por objeto o conceito de "transtorno" e aprofunda as transformações em curso no campo psiquiátrico desde os anos 1950. A lógica classificatória psiquiátrica vigente a partir dos anos 1980, cujo modo de produção de conhecimento está intrinsecamente vinculado ao complexo médico-industrial, e, em particular, à indústria farmacêutica, parece responder historicamente às demandas de produção de novas táticas de regulação social, uma vez que as táticas disciplinares começavam a dar sinais de esgotamento.

Em um mundo que se seguiu ao profundo questionamento das relações de poder presente nas instituições modernas (FOUCAULT, 1972/1984, 19731974/2006; 1976/2005; GOFFMAN, 2001), no âmbito da vida privada (relações conjugais e filiais), quanto ao âmbito da vida pública (escola, universidade, instituições totais) e, ao mesmo tempo, que se viu em novas encruzilhadas neoliberais do descompasso entre o igualitarismo (ELIACHEFF, LARIVIÈRE, 2007) e o "refugo humano" (BAUMAN, 2004) era necessário rever a produção de normas que pudessem atender às novas exigências daí decorrentes. Normalizar, pela via da gestão dos riscos, passa a ser a estratégia política privilegiada na contenção dos desvios indesejáveis, que se pulverizam no tecido social, através daquilo que Foucault (1977-1978/2004) denominou de “dispositivo de segurança”. 
A volatilidade epistemológica do conceito de "transtorno mental" é um artefato engendrado nesta nova forma de politização da vida na atualidade, já que ele torna mais maleável as fronteiras do normal e do patológico para que a presunção de risco individual e social seja o fiel da balança no raciocínio normalizador da psiquiatria neokraepeliniana de nossos dias.

Como procuramos demonstrar ao longo do trabalho, as controvérsias entre psiquiatria e psicanálise repousam sobre tensões ético-políticas que são transversais ao que costumamos a denominar de modernidade e de inquestionável atualidade. Ao recuperar esta memória, o que se pretende é problematizar solidariedades entre esses dois campos que reforçam o que, por princípio, se quer contestar. Contra a normalização calcada no organicismo, ressaltemos um dos legados de Canguilhem (1943/2006), traduzido e sintetizado por Foucault (1985/2001, p.1593) como: "no limite, a vida — em sua marca radical —é o que é capaz de errância"4 . Nisso reside nossa possibilidade de existir e de resistir.

Recebido em 26/6/2014. Aprovado em 1/9/2014.

\section{REFERÊNCIAS}

BAUMAN, Z. (2005) Vidas desperdiçadas. 2 ed. Rio de Janeiro: Zahar.

BECHERIE, P. (1985). Os fundamentos da clínica: história e estrutura do saber psiquiátrico. São Paulo: Jorge Zahar.

BICHAT, M.F.X. (1805). Recherches psysiologiques sur la vie et la mort. Paris: Brosson/Gabon. Disponível em: http://www.arcliive.org/ details/recliercliespliysiOObicli. Acesso em 20/6/2014.

BIRMAN, J. (2007) A biopolítica na genealogia da psicanálise: da salvação à cura. História, Ciências, Saúde — Manguinhos, Rio de Janeiro, v.14, n.2, p.529-548.

(2003) O mal-estar na atualidade: a psicanálise e as novas formas de subjetivação. 4 ed. Rio de Janeiro: Garamond.

. (2000) Entre cuidado de si e saber de si: sobre Foucault e a psicanálise. Rio de Janeiro: Relume-Dumará.

. (2001) Gramáticas do erotismo: a feminilidade e as formas de subjetivação em psicanálise. Rio de Janeiro: Civilização Brasileira.

CANGUILHEM, G. (1943/2006) O normal e o patológico. 6 ed. Rio de Janeiro: Forense Universitária.

COFFIN, J-C. (2003) La transmission de la folie (1850-1914). Paris:L'Harmattan.

DERRIDA, J. (2001) Mal de arquivo: uma impressão freudiana. Rio de Janeiro: Relume-Dumará.

ELIACHEFF, D.S. \& LARIVIÈRE, C. (2006) Les temps des victimes. Paris: Albin Michel.

\footnotetext{
${ }^{4}$ Tradução livre de: “à la limite, la vie — de là son caractere radical — c'est qui é capable d'erreur" (Foucault, 1984/1985, p.1593).
} 
FOUCAULT, M. (1976/2005) História da sexualidade I: a vontade de saber. Trad. e org. de Roberto Machado. 16 ed. Rio de Janeiro: Graal.

(1985/2001) "La vie: l'expérience et la science", in Dits et écrits II. Paris: Gallimard, p.774-775.

(1977-1978/2004). “Sécurité, Territoire, Population: Cours au Collège de France (1977-1978). Paris: Seuil/Gallimard.

(1974-1975/2001) Os anormais. São Paulo: Martins Fontes.

(1973-1974/2006) O poder psiquiátrico: curso no Collège de France. São

Paulo: Martins Fontes.

(1972/1984). Vigiar e punir: história da violência nas prisões. 3 ed. Petrópolis: Vozes.

(1967/2005) A arqueologia do saber. 7 ed. Rio de Janeiro: Forense. FREUD, S. (1918/1995). Entrevista a uma jornalista húngara, in SOUZA, Paulo César de (Org.). Freud, Nietzsche e outros alemães. Rio de Janeiro: Imago, p.57.

(1926/1995). O valor da vida: entrevista a George Sylvester

Viereck, in ALTMAN, Fábio (Org.) A arte da entrevista: uma antologia de 1823 aos nossos dias. São Paulo: Scritta.

(1988) Edição standard brasileira das obras psicológicas completas de Sigmund Freud. Rio de Janeiro: Imago.

(1894) “As neuropsicoses de defesa”, v.3, p.50-66.

(1896a) "Hereditariedade e a etiologia das neuroses", v.13, p.140-155.

(1896b) "Observações adicionais sobre as neuropsicoses de defesa", v.3, p.151-173.

(1898) “A sexualidade na etiologia das neuroses”, v.3, p.248-270.

(1905) "Três ensaios sobre a teoria da sexualidade”, v.7, p.14-116.

(1915) “A pulsão e suas vicissitudes”, v.14, p.117-144.

(1897) “Carta 75”, v.1, p.318-323.

(1908) “Moral sexual 'civilizada' e doença nervosa moderna”, v.9, p.165-186.

(1910) “A concepção psicanalítica da perturbação psicogênica da visão”, v.11, p.217-228.

(1914) "Sobre o narcisismo: uma introdução", v.14, p.77-113.

(1920) “Além do princípio do prazer”, v.18, p.13-75.

GOFFMAN, E. (2003) Manicômios, conventos e prisões. 7 ed. São Paulo: Perspectiva.

MAGNAN, V. (1876) Recherches sur les centres nerveux. Paris: G. Masson.

MOREL, B.A. (1857) Traité de dégénérescences physiques, intellectuelles et morales de l'espece humaine. Paris: Ballière.

NUNES, S. (2000) O corpo do diabo entre a cruz e a caldeirinha: um estudo sobre a mulher, o masoquismo e a feminilidade. Rio de Janeiro: Civilização Brasileira.

SERPA-JUNIOR, O.D. (1998) Mal-estar na natureza: estudo crítico sobre o reducionismo biológico em psiquiatria. Rio de Janeiro: Te Corá.

SPITZER, R. (1980) “Introduction”, in American Psychiatric Association (APA). Diagnostic and Statistical Manual of Mental Disorders. Washington: APA.

Cristiane Oliveira

cristianeoliveira@ufba.br 
